\title{
Genome-wide search reveals a novel GacA-regulated small RNA in Pseudomonas species Nicolas González ${ }^{1}$, Stephan Heeb², Claudio Valverde ${ }^{1,4}$, Elisabeth Kay ${ }^{1,5}$, Cornelia Reimmann ${ }^{1}$, Thomas Junier ${ }^{3}$ and Dieter Haas*1
}

\begin{abstract}
Address: ${ }^{1}$ Département de Microbiologie Fondamentale, Biophore, Université de Lausanne, CH-1015 Lausanne, Switzerland, ${ }^{2}$ Institute of Infection, Immunity and Inflammation, Center for Biomolecular Sciences, University of Nottingham, Nottingham NG7 2RD, UK, ${ }^{3}$ Department of Genetic Medicine and Development, University of Geneva, Rue Michel-Servet 1, CH-1211 Geneva, Switzerland, ${ }^{4}$ Departamento de Ciencia y Tecnología, Programa Interacciones Biológicas, Universidad Nacional de Quilmes, Saenz Peña 352, Bernal B1876BXD, Argentina and ${ }^{5}$ UMR5163/ CNRS-UJF, Institut Jean-Roget, Grenoble, France

Email: Nicolas González - nicolasgael.gonzalez@unil.ch; Stephan Heeb - stephan.heeb@nottingham.ac.uk; Claudio Valverde - cvalver@unq.edu.ar; Elisabeth Kay - elisabeth.kay@ujf-grenoble.fr; Cornelia Reimmann - cornelia.reimmann@unil.ch; Thomas Junier - thomas.junier@medecine.unige.ch; Dieter Haas* - dieter.haas@unil.ch

* Corresponding author
\end{abstract}

Published: 13 April 2008

BMC Genomics 2008, 9:167 doi:10.1186/147|-2164-9-167

This article is available from: http://www.biomedcentral.com/147/-2/64/9/167

(C) 2008 González et al; licensee BioMed Central Ltd.

This is an Open Access article distributed under the terms of the Creative Commons Attribution License (http://creativecommons.org/licenses/by/2.0), which permits unrestricted use, distribution, and reproduction in any medium, provided the original work is properly cited.
Received: 12 November 2007

Accepted: 13 April 2008

\begin{abstract}
Background: Small RNAs (sRNAs) are widespread among bacteria and have diverse regulatory roles. Most of these sRNAs have been discovered by a combination of computational and experimental methods. In Pseudomonas aeruginosa, a ubiquitous Gram-negative bacterium and opportunistic human pathogen, the GacS/GacA two-component system positively controls the transcription of two sRNAs (RsmY, RsmZ), which are crucial for the expression of genes involved in virulence. In the biocontrol bacterium Pseudomonas fluorescens CHAO, three GacA-controlled sRNAs (RsmX, RsmY, RsmZ) regulate the response to oxidative stress and the expression of extracellular products including biocontrol factors. RsmX, RsmY and RsmZ contain multiple unpaired GGA motifs and control the expression of target mRNAs at the translational level, by sequestration of translational repressor proteins of the RsmA family.
\end{abstract}

Results: A combined computational and experimental approach enabled us to identify 14 intergenic regions encoding sRNAs in $P$. aeruginosa. Eight of these regions encode newly identified sRNAs. The intergenic region 1698 was found to specify a novel GacA-controlled sRNA termed RgsA. GacA regulation appeared to be indirect. In P. fluorescens CHAO, an RgsA homolog was also expressed under positive GacA control. This 120-nt sRNA contained a single GGA motif and, unlike RsmX, RsmY and RsmZ, was unable to derepress translation of the hcnA gene (involved in the biosynthesis of the biocontrol factor hydrogen cyanide), but contributed to the bacterium's resistance to hydrogen peroxide. In both $P$. aeruginosa and $P$. fluorescens the stress sigma factor RpoS was essential for RgsA expression.

Conclusion: The discovery of an additional sRNA expressed under GacA control in two Pseudomonas species highlights the complexity of this global regulatory system and suggests that the mode of action of GacA control may be more elaborate than previously suspected. Our results also confirm that several GGA motifs are required in an sRNA for sequestration of the RsmA protein. 


\section{Background}

In bacteria, > 150 non-coding small RNAs (sRNAs) have been described [1]. The first bacterial sRNAs were discovered in Escherichia coli, either fortuitously due to their abundance or by the observation of phenotypes conferred by their overexpression. Some abundant and stable sRNAs were found early in gel electrophoretic analysis. They include 4.5 S RNA, which is implicated in protein export; a component of RNase $\mathrm{P}$, which participates in tRNA processing; and tmRNA, which has an important role in translational quality control [2]. The majority of sRNAs was identified by systematic approaches, principally in $E$. coli. Computational searches mainly focused on intergenic regions (IgRs) and were combined with predictions of promoters and of rho-independent transcription terminators [3,4]. The QRNA algorithm, which takes into account the sequence homology of IgRs in closely related species as well as conserved secondary structures [5], was combined with experimental methods to identify several sRNAs, e.g. those involved in sporulation of Bacillus subtilis [6].

Most bacterial sRNAs studied have regulatory roles in gene expression, occurring in many instances at a post-transcriptional level. In one type of post-transcriptional regulation, which is usually governed by the RNA chaperone Hfq in Gram-negative bacteria, sRNAs interact with specific mRNA targets, thereby modifying the accessibility of the Shine-Dalgarno sequence to the translational machinery and often altering the stability of the mRNA. For instance, in E. coli, the iron-containing superoxide dismutase SodB is regulated by iron availability via the sRNA RyhB, which base-pairs with sodB mRNA. This interaction blocks ribosome access and favors nucleolytic degradation of the mRNA [7]. A second type of post-transcriptionally active sRNAs interacts with RNA-binding regulatory proteins of the RsmA/CsrA family. RsmA (regulator of secondary metabolism) and CsrA (carbon storage regulator) can act as translational repressors; sRNAs having high affinity for these proteins are therefore able to relieve translational repression by sequestering them [8].

In pseudomonads, few sRNAs have been studied. In P. fluorescens, the sRNAs RsmX, RsmY and RsmZ were detected by their binding capacity to the regulatory protein RsmA $[9,10]$, by their sequence similarity with already identified sRNAs [11], or by multicopy suppression of a gacA mutation [12]. The GacS/GacA two-component system (which is homologous to BarA/UvrY in E. coli) activates the transcription of these three sRNAs. When they are present in high concentrations, they titrate the RNA-binding proteins RsmA and its homolog RsmE, resulting in enhanced translational expression of genes involved in biocontrol of plant root diseases and in resistance to oxidative stress $[10,13,14]$. Biocontrol factors of strain CHA0 are second- ary metabolites (e. g., hydrogen cyanide [HCN]) and lytic exoenzymes [15]. In P. aeruginosa, the Gac/Rsm system involves two sRNAs, RsmY and RsmZ [16]. As part of the quorum sensing machinery this regulatory system not only controls the expression of genes specifying exoproducts such as HCN, pyocyanin and elastase, but also upregulates the expression of the rhli gene, which codes for the enzyme synthesizing the quorum sensing signal $N$ butanoyl-homoserine lactone $[17,18]$. Furthermore, a search for Fur-box motifs in IgRs of $P$. aeruginosa led to the discovery of two iron-regulated sRNAs, PrrF1 and PrrF2 [19]. More recently, a study using a program that combines several predictive features mentioned above revealed a total of 17 sRNAs in strain PAO1 [20].

We have begun to search for new GacA-regulated sRNAs in Pseudomonas spp., by applying the QRNA method to IgRs of various Pseudomonas spp., combined with a prediction of rho-independent terminators and, where appropriate, putative promoters. Eight sRNAs were newly identified in $P$. aeruginosa by Northern blotting experiments. By comparing sRNA expression in the wild-type with that in a gacA mutant, we discovered a novel GacA-controlled sRNA termed RgsA. We analyzed its regulation and involvement in biocontrol factor expression and oxidative stress response in P. fluorescens CHA0. Moreover, we show that RgsA expression in $P$. aeruginosa and $P$. fluorescens strictly depends on the stress sigma factor RpoS.

\section{Results}

Prediction and screening of sRNAs in P. aeruginosa PAOI The majority of the bacterial sRNA genes found to date is located in IgRs $[3,21]$ and the size of the sRNAs generally varies between 50 and 400 nt $[1,22]$. Accordingly, we based our search for sRNAs in P. aeruginosa PAO1 on the criterion that sRNA genes should be located in IgRs that are larger than $50 \mathrm{bp}$. A total of 3168 IgRs fulfilled this condition. We then assumed that functional sRNA sequences should be conserved in closely related species $[4,20,23]$ and we used BLASTn to search for sequences that are homologous to the 3168 IgRs of $P$. aeruginosa in the genomic sequences of five related pseudomonads (Pseudomonas putida KT2440, Pseudomonas syringae pv. tomato DC3000, Pseudomonas fluorescens Pf0-1, P. fluorescens SBW25 and P. fluorescens Pf-5). Only those PAO1 IgRs were selected that shared more than $65 \%$ sequence identity with a genomic sequence of at least one other pseudomonad. The alignments resulting from the BLAST program were then subjected to QRNA analysis [5]. In pairwise alignments of homologous sequences, this algorithm evaluates pairs of nucleotide substitutions and calculates their probabilities of having structural or codon usage conservation and discriminates sequence pairs without a sufficient number of substitutions. RNAs having substitutions with a bias towards codon usage are likely to 
code for polypeptides whereas pairs of substitutions that maintain stem-loop structures have a higher probability to reflect secondary structure conservation of non-coding RNAs. Although the sequences subjected to BLASTn analysis consisted only of intergenic, non-coding regions according to the $P$. aeruginosa $\mathrm{PAO} 1$ genome annotations, sequences whose coding probabilities calculated by QRNA were found to be high were nevertheless retained for further analysis. By applying QRNA in this way, 162 out of the initial 3168 IgRs from $P$. aeruginosa PAO1 were retained (see Table in Additional file 1). Among these 162 IgRs, 32 were found to contain exclusively tRNA or rRNA genes and were not considered further. In the 130 remaining regions, the presence of rho-independent terminators was assessed using TransTerm [24] set at a confidence cutoff of $93 \%$ (i.e., expecting $93 \%$ of all predictions to be correct).

\section{Experimental observation of sRNAs in P. aeruginosa PAOI}

IgRs occurring in $P$. aeruginosa and at least two other pseudomonads and having recognizable promoter elements (e.g., for the housekeeping sigma factor RpoD or the stress sigma factor RpoS) were preferentially chosen for Northern blot analysis. Cultures of $P$. aeruginosa PAO1 were grown in nutrient yeast broth (NYB) to exponential or stationary phase and total RNA was extracted. Northern blot analysis was carried out with digoxigenin (DIG)-labeled probes, each covering an entire IgR. Among 49 IgRs thus analyzed, 14 were reproducibly found to express sRNAs (Table 1). Figure 1 shows all transcripts revealed, except for four sRNAs that had been described previously: $4.5 \mathrm{~S}$ RNA (encoded by the ffs gene in IgR 888) [2,25], an RNase $P$ component found in many bacteria (encoded by $r n p B$ in IgR 2510) [2,20], and PrrF1 and PrrF2 found in P. aeruginosa (encoded by prrF1 and prrF2 in IgR 2667) [19]. They were considered to validate the method and not investigated further. Three additional sRNAs (encoded by IgRs 491, 1698, 1887; Table 1) are among the 17 P. aeruginosa sRNAs described by Livny et al. [20]. In that study, the three sRNAs are designated P5, P16 and P20, respectively. In conclusion, we detected eight new sRNAs encoded by the remaining IgRs.

All transcripts were also detected when cells had been cultivated in the iron-limited medium GGP or in the minimal medium MME (data not shown), except for 1559 sRNA, which was not tested in these alternative media. Six regions (IgRs 491, 622, 1059, 1559, 1698, 2315) produced more than one transcript (Figure 1); we only indicate the most prevalent bands in this figure. Multiple transcripts can be due to processed sRNAs, 5' leader mRNA sequences or 3' mRNA fragments related to flanking genes [26]. Three other regions (IgRs 1714, 1887, 2626) each revealed a major band, together with possible degradation products. Whenever the sRNA transcript

Table I: sRNAs transcripts observed in $P$. aeruginosa PAOI

\begin{tabular}{|c|c|c|c|c|c|c|c|c|}
\hline \multirow[t]{2}{*}{ Intergenic region a } & \multirow{2}{*}{$\begin{array}{c}\text { Coordinates in PAOI } \\
\text { genome }(b p)\end{array}$} & \multicolumn{2}{|c|}{$5^{\prime}$ gene } & \multicolumn{2}{|c|}{ 3' gene } & \multicolumn{3}{|c|}{ sRNA } \\
\hline & & Length (bp) & Dir.b & Length (bp) & Dir. ${ }^{b}$ & Predicted length (nt)c & Observed length (nt)d & Dir.g \\
\hline 491 & $912780-913085$ & 1185 & $<$ & 486 & $>$ & 90 & 100,200 & $>$ \\
\hline 622 & I|40860-||4|267 & 1146 & $>$ & 465 & $>$ & & 200,300 & $?$ \\
\hline 645 & $1204782-1205770$ & 1149 & $>$ & 1767 & $>$ & $300 \pm 10$ & 300 & $<$ \\
\hline $888=f f s$ & $1668833-1669085$ & 378 & $>$ & 867 & $<$ & 113 & 90 & $>$ \\
\hline 1059 & 1996807-1997508 & 1659 & $<$ & 1041 & $<$ & & $150,200,300$ & $?$ \\
\hline 1466 & $2918212-2918965$ & 1041 & $>$ & 534 & $<$ & & 300 & $?$ \\
\hline 1559 & $3|12| 5|-3| 12876$ & 519 & $>$ & 900 & $>$ & & $250,300 \mathrm{e}$ & $?$ \\
\hline $1698=r g s A$ & $33|8657-33| 888 \mid$ & 1134 & $>$ & 777 & $<$ & $120 \pm 10$ & 100,300 & $>$ \\
\hline 1714 & $3360654-3360873$ & 1386 & $<$ & 3474 & $>$ & & 200 & $?$ \\
\hline 1887 & $3705|6|-3705888$ & 1995 & $<$ & 603 & $<$ & $210 \pm 10$ & 200 & $<$ \\
\hline 2315 & $4536493-4536919$ & 660 & $<$ & 1122 & $<$ & $160 \pm 10$ & 180 & $<$ \\
\hline $2510=r n p B$ & $4956029-4956732$ & 452 & $<$ & 849 & $<$ & 208 & 200 & $<$ \\
\hline 2626 & $5196833-5197184$ & 1464 & $>$ & 576 & $>$ & & 200 & $>$ \\
\hline $2667=p r r F I, 2$ & $5283906-5284368$ & 798 & $>$ & 888 & $<$ & 110,110 & $100,110^{f}$ & $>$ \\
\hline
\end{tabular}

\footnotetext{
a Transcripts that were also found by Livny et al. [20] are shown in boldface

b Dir., direction of flanking genes

c Lengths of transcripts described in other studies are indicated by their experimental values; otherwise, predicted lengths are estimates \pm 10 nt

d Bands that were observed in cells grown in NYB, GGP or MME medium; estimated size $\pm 10 \mathrm{nt}$

e Not tested in GGP and MME medium

${ }^{f}$ No transcript was observed in cells grown in NYB or GGP in exponential phase; transcripts were present in stationary phase cells grown in all media

$\mathrm{g}$ Dir., direction of sRNA genes. When rho-independent terminators are predicted to be present, the direction of the sRNA is annotated (> or $<$ ). When the direction is unknown, this is indicated by a question mark
} 

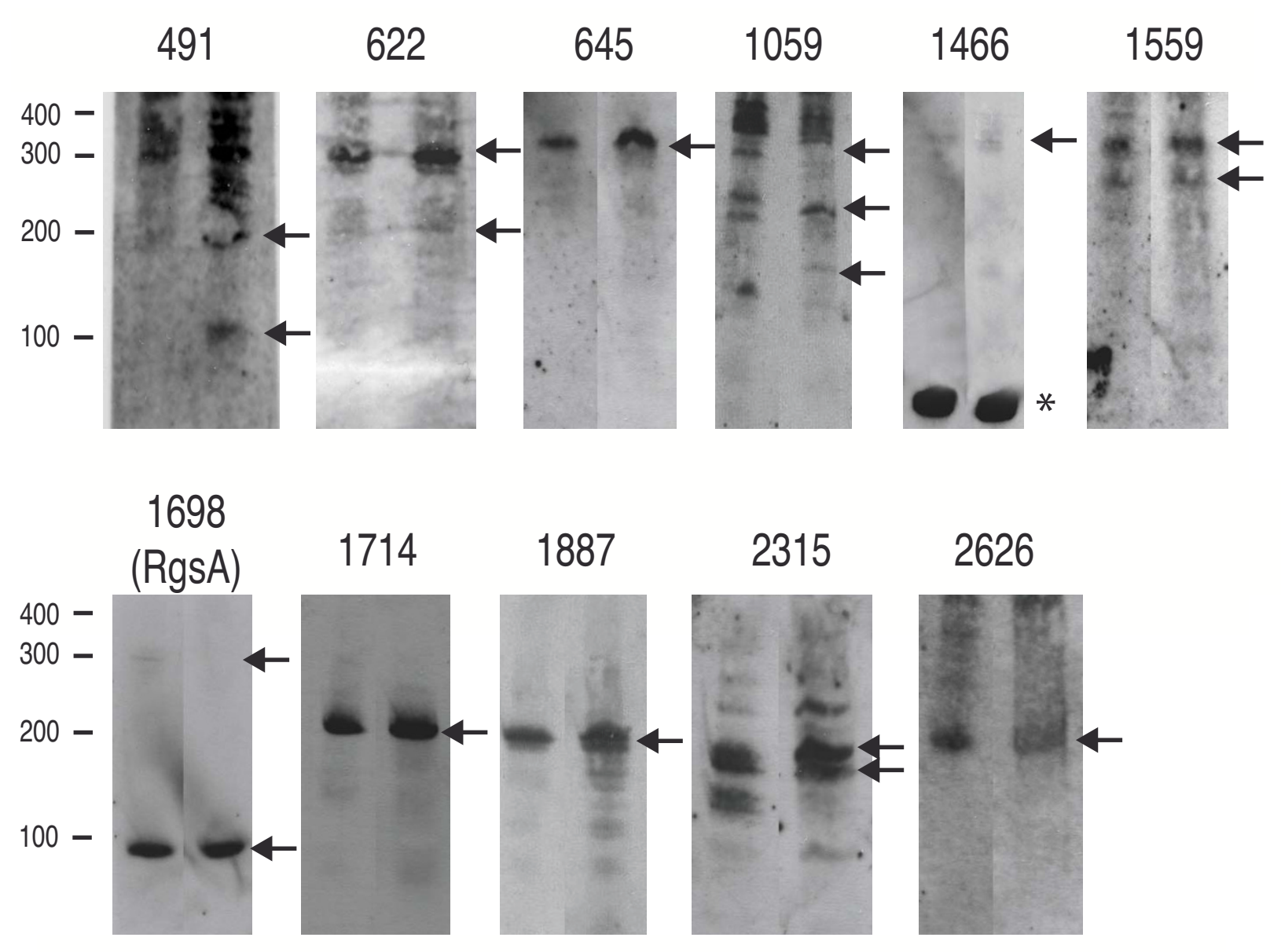

Figure I

Detection of sRNAs in $\boldsymbol{P}$. aeruginosa by Northern blots. Total RNA was purified from cultures of $P$. aeruginosa strain PAOI grown in NYB until exponential phase (first lane in each blot) and stationary phase (second lane in each blot). Experimental conditions are described in Methods. The blots for the annotated sRNA genes encoding 4.5S RNA (in IgR 888), RNase P RNA (in IgR 25I0) and PrrFI, 2 (in IgR 2667) are not shown. The approximate positions of RNA standards are shown on the left. The main transcripts are pointed out by arrows. A tRNACys gene is embedded in the IgR I466; its transcript is indicated by an asterisk.

length could be predicted with reasonable certainty (Table $1)$, at least one of the main transcripts observed had the expected size (Figure 1). IgR 491 specified a transcript that had previously been observed [20]; we deduce from the sequence that it originates from an RpoS-dependent promoter. The 180-nt sRNA encoded by IgR 2315, which is located between the $r i b C$ and $r i b D$ genes, is a homolog of sro $G$, a transcript resulting from the cleavage of a riboswitch element found upstream of ribB in E. coli [27]. The $P$. aeruginosa sroG homolog was slightly longer than the sroG transcript in E. coli (147 nt) [27]. The 2315 sRNA of $P$. aeruginosa may be involved in regulation of riboflavin biosynthesis, by analogy with the homologous element in E. coli $[28,29]$. In four cases (IgRs 645, 1698, 1887, and 2315), the coordinates of the sRNA genes can be deduced either from recognizable promoter and terminator ele- ments or by sequence comparison with an E. coli RNA (Additional file 2 for the IgRs).

\section{GacA- and RpoS-regulated expression of the 1698 sRNA in $P$. aeruginosa $P A O I$ and $P$. fluorescens $C H A O$}

The expression of the 11 sRNAs shown in Figure 1 was tested in the P. aeruginosa gacA mutant PAO6281 by Northern blotting. The 1698 sRNA was the only transcript that showed a significantly decreased expression in the gacA mutant, compared with that in the wild-type PAO1 (data not shown). This 120-nt transcript was further characterized. It was virtually absent from strain PAO1 during the exponential phase, but was produced abundantly in the stationary phase. In the gacA mutant, the expression of the 1698 sRNA was about two-fold lower than in the wildtype (Figure 2a), suggesting positive regulation by GacA. 
a

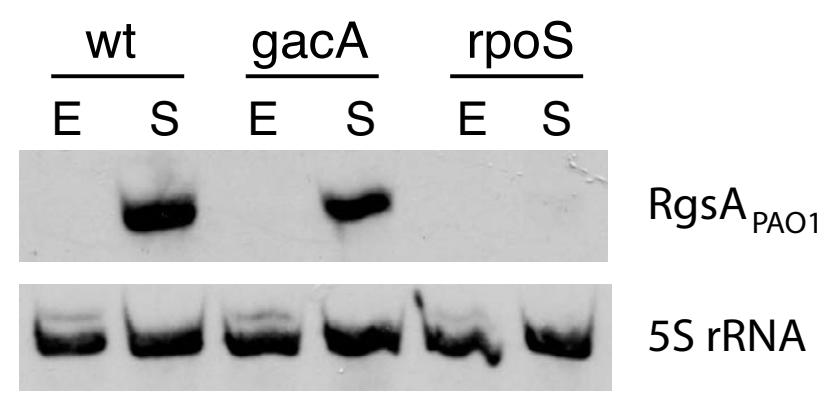

b

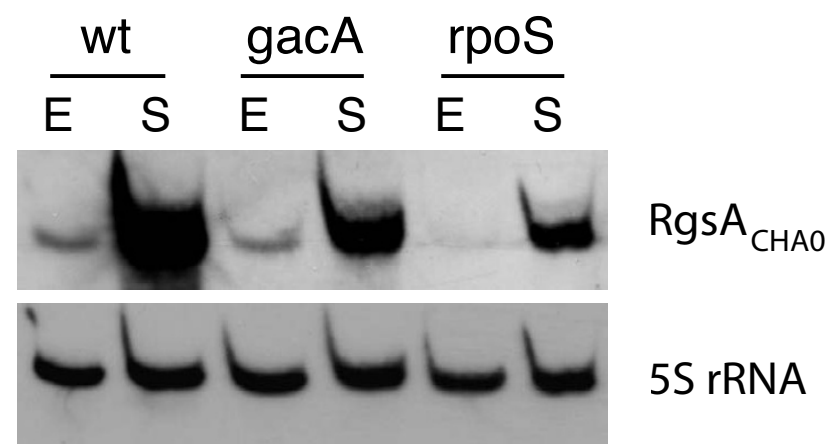

C

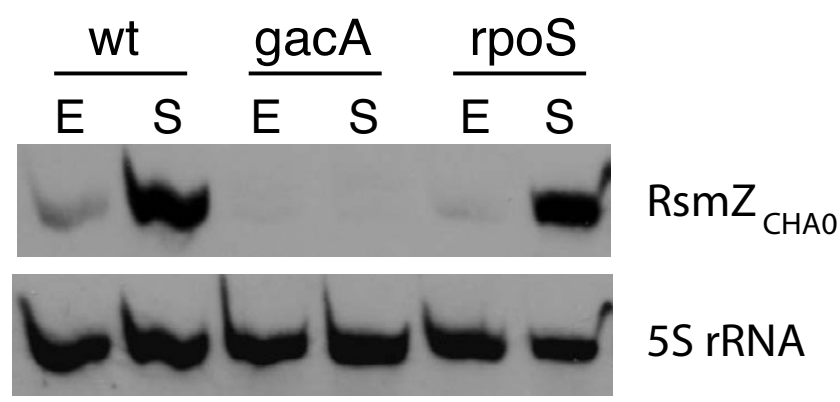

\section{Figure 2}

Detection of transcriptional control of RgsA (1698) sRNA in P. aeruginosa and in P. fluorescens by Northern blot. a. Hybridization of cross-linked total RNA from P. aeruginosa PAOI (wt), PAO628I (gacA mutant) and PAOI-rpoS (rpoS mutant) with a double-stranded DNA probe prepared with primers I698F (PAOI) and I698R (PAOI) (additional file 3). RNA preparations were obtained from PAOI (wild-type) in exponential phase $\left(\mathrm{OD}_{600} \cong 0.8\right)$ and stationary phase $\left(O \mathrm{O}_{600} \cong 4.9\right)$; from PAO628I (gacA) in exponential phase $\left(\mathrm{OD}_{600} \cong 0.7\right)$ and stationary phase $\left(\mathrm{OD}_{600} \cong 4.8\right)$; from PAOI-rpoS (rpoS) in exponential phase $\left(\mathrm{OD}_{600} \cong 0.7\right)$ and stationary phase $\left(\mathrm{OD}_{600} \cong 5.0\right)$.b. Hybridization cross-linked total $\mathrm{RNA}$ from $P$. fluorescens CHAO (wt), CHA89 (gacA mutant) and CHA8I5 (rpoS mutant) with a double-stranded DNA probe prepared with primers $1698 \mathrm{~F}$ (CHA0) and I698R (CHA0) (additional file 3). RNA was extracted from CHA0 (wild-type) in exponential phase $\left(\mathrm{OD}_{600}\right.$ $\cong 0.5)$ and stationary phase $\left(\mathrm{OD}_{600} \cong 6\right) ; \mathrm{CHA} 89(\mathrm{gacA})$ in exponential phase $\left(\mathrm{OD}_{600} \cong 0.6\right)$ and stationary phase $\left(\mathrm{OD}_{600} \cong 6\right)$; CHA8I $5(r p o S)$ in exponential phase $\left(O D_{600} \cong 0.6\right)$ and stationary phase $\left(O_{600} \cong 5.0\right)$. c. Hybridization of the same RNA preparations from P. fluorescens as in $\mathbf{b}$, with an RsmZ probe synthesized with primers RsmZF (CHAO) and RsmZR (CHA0) (additional file 3). As a loading control, $5 \mathrm{~S}$ rRNA was revealed in all samples with a probe synthesized with primers $5 \mathrm{~S}$ rRNA-I and $5 \mathrm{~S}$ rRNA-2 (additional file 3). E: exponential phase, S: stationary phase. 
Moreover, in a mutant lacking the stress/stationary phase sigma factor RpoS, PAO1-rpoS [30], no expression of this RNA was detected (Figure 2a). We therefore named this sRNA RgsA (for regulation by GacA and stress).

The RgsA sRNA was also observed in P. fluorescens CHA0 (Figure 2b), a strain closely related to P. fluorescens Pf-5, whose genome has been sequenced. There is $99 \%$ identity between the two P. fluorescens strains for the IgR 1698 (Figure 3a). In strain CHA0, the band corresponding to this sRNA was faint in the wild-type CHA0, the gacA mutant CHA89 and the rpoS mutant CHA815 during the exponential phase. In the stationary phase, the transcript was observed clearly in the wild-type, whereas the expression was strongly reduced in the gacA mutant and in the rpoS mutant (Figure 2b), suggesting that again both GacA and RpoS contribute to the regulation of RgsA RNA.

As a control, we included the RsmZ sRNA of strain CHAO in this Northern blot analysis. Confirming earlier results [9], we see that $r s m Z$ expression depends on positive control by GacA, but is independent of RpoS (Figure 2c).

\section{Location of the rgsA gene in pseudomonads}

The rgs A gene is strongly conserved in seven related pseudomonads (Figure 3a). The promoter, the rho-independent terminator and a putative upstream regulating sequence (URS) show extensive sequence similarities. The transcription start site was tentatively deduced from the consensus - 10 element (T/G CTATACT) of RpoS-dependent promoters [31]. The presence of this RpoS promoter element is in agreement with our finding that RgsA sRNA was absent from an rpoS mutant of $P$. aeruginosa and that a reduced amount of this sRNA was present in an rpoS mutant of $P$. fluorescens(Figures $2 \mathrm{a}$ and $2 \mathrm{~b}$ ). In a database search, we did not find any sequence that is highly similar to the entire conserved URS sequence, suggesting that it might be a binding site for a specialized rather than for a global regulator. In particular, the URS motif is not related to the palindromic upstream activating sequence which is located upstream of the $r s m X, r s m Y$ and $r s m Z$ genes and which is a potential GacA binding site $[11,16]$. We therefore suspect that the GacA effect on RgsA expression is likely to be indirect. The predicted size of RgsA (120 nt) agrees well with the length of the 1698 transcript observed in the initial Northern blots (Figure 1).

The genomic context of the rgsA gene in P. fluorescens Pf-5 and CHAO is shown in Figure $3 \mathrm{~b}$. The flanking ORF PFL_1804 (coding for a regulator of the TetR family), which is located 800 bp upstream, is conserved only in $P$. putida KT2440. The downstream, divergently transcribed ORF PFL_1803 (a homolog of the E. coli tatD gene) is conserved in all Pseudomonas strains sequenced to date. In E. coli, the tatD product exhibits Mg-dependent DNase activ- ity, but is not required for protein transport by the Tat pathway, contrary to what was originally expected [32].

\section{Regulation of rgsA gene expression in $\mathrm{P}$. aeruginosa PAOI and P. fluorescens CHAO}

To monitor the rgs $A$ regulation by GacA during growth, we constructed $r g s A_{P A O 1}-l a c Z$ and $r g s A_{C H A O}-l a c Z$ transcriptional fusions in plasmids pME7235 and pME7234, respectively. The primers used for these constructions (Figure 3b) carry a BamHI site, which enabled us to place the lac $Z$ gene under the control of the respective rgsA promoter. At low cell population densities, the wild-type strains PAO1 and CHAO as well as the gacA mutants PAO6281 and CHA89 exhibited similar basal levels of lacZ expression from the rgsA-lac $Z$ constructs (Figures $4 a$ and $4 \mathrm{~b}$ ). At high cell population densities, the gacA mutants showed an approximately two-fold reduction of $\beta$-galactosidase activity, compared with the activity in the wild-type strain. This finding is consistent with the Northern blot results (Figures $2 \mathrm{a}$ and $2 \mathrm{~b}$ ). The $\mathrm{rgs}_{\mathrm{CHAO}}-\mathrm{lacZ}$ fusion carried by pME7234 was also assayed in the rpoS mutant CHA815; at $\mathrm{OD}_{600} \approx 4.0$, this fusion showed a $40 \%$ decrease of lacZ expression, compared with that in the wild-type CHAO (data not shown). In conclusion, transcription of the rgs $A$ gene is probably activated indirectly by GacA and directly by RpoS, which is assumed to bind to the -10 promoter element (Figure $3 \mathrm{~b}$ ), both in $P$. aeruginosa and in P. fluorescens.

\section{Role of RgsA sRNA in the Gac/Rsm regulatory cascade of P. fluorescens CHAO}

A single, typical RsmA-binding motif (ANGGA) was found in an unpaired region of the RgsA sRNA of strain CHAO (Figure 5). The GacA-controlled sRNAs RsmX, RsmY and RsmZ and their functional homologs each contain several GGA and extended ANGGA motifs [8]. In the case of RsmY, these motifs have been shown to be essential for sequestration of RsmA and its homolog RsmE in $P$. fluorescens [33]. We therefore investigated whether the RgsA sRNA might also have a titrating role, by testing whether rgsA overexpression would enhance the expression of a translational $h c n A^{\prime}$-'lacZ fusion in P. fluorescens CHA0. Expression of hcnA, the first gene of the hon operon involved in HCN biosynthesis, is tightly controlled by the Gac/Rsm cascade in strain CHA0. In an $r s m X$ rsmY rsmZ triple mutant, artificial overexpression of $r s m X$ rescues hcnA'-'lacZ expression [10]. We measured the expression of a chromosomal hcnA'-'lacZ fusion in the wild-type background and in the rsmXYZ triple mutant where the activity was almost totally lost (Figure $4 \mathrm{c}$ ). When $\mathrm{rgs}_{\mathrm{CHAO}}$ was overexpressed in the wild-type strain (CHA207/ pME7236), no significant difference was observed, compared with the native context (CHA207 containing the empty vector pME6032). Similarly, the $r g s A_{C H A O}$ overexpressing plasmid pME7236 was unable to elevate honA'- 
a

PfO-1
PputKT2 440
Pf-5
PsyrDC3000
PAO1
PfSBW25
Pf CHA0

Pf0-1

PputKT2440

Pf-5

PsyrDC3000

PAO1

PfSBW25

Pf CHAO

Pf0-1

PputKT2440

Pf-5

PsyrDC3000

PAO1

PfSBW25

Pf CHAO

Pf0-1

PputKT2440

Pf -5

PsyrDC3000

$\mathrm{PAO} 1$

PfSBW25

Pf CHAO
URS

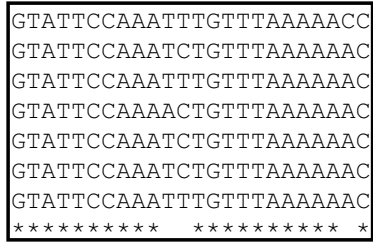

\begin{tabular}{|c|c|}
\hline & -35 \\
\hline CGGCCGGCTA & CTGGAC \\
\hline CCAATATGCZ & CTGG-C \\
\hline AGCAGGGGCAA & ETGGAC \\
\hline CCAAAAGACA & ETGGAC \\
\hline CAGCCCTGT & ETGGAC \\
\hline $\mathrm{AGTCGCGA}$ & FTGGAC \\
\hline CAGGGGC & $\begin{array}{l}\text { TTGGAC } \\
* * * * *\end{array}$ \\
\hline
\end{tabular}

-10 (RpoS)

CGGCGCCAGAC- TGATCAA 61 CTGCGCCAAACOIGACCAA 61 GAATGCAATAG-TGATCAA 61 GGCGGCCCGTCC-IGAGCAA 61 SCCCACGA-ACA IGACCAA 61 GAATCGGATAC-TGATCAA 61 $* * * * * * * * * * \quad * * * * * * * * * *$

$\rightarrow+1$

TACTP-GAACTGTCGG---GCGACATCTCCCCCA-AGTGTCGCGCCGGTAAAGGTACCAA 116 TACT P-GAAGTGTTGGC--GCGGCGCATCCCCCCCAGTGGCGCGCCGATAAAGGTGCTCA 118 TACT T-CAACTGTCGGC--GGGACATCTCCCCCA-AGTGAAACGCCGATCAAGGTACCGA 117 TACT PATAAGCGCTGAC--GCGTCATATCCCCCA-AATGACTCGCCAGTGGAGGTGCCAA 118 TACT GAAAGGTACTGGCGCGCGGTATCTCCCCCCAAGTACCCAGCCAGTGAAGGTACCGA 121 TACT P-CAACTGTCGGC--GTGACATCTCCCCCA-AGTGAAGCGCTGACCTGGGTACCAA 117 TACT P-CAACTGTCGGC--GGGACATCTCCCCCA-AGTGAAACGCCGATCAAGGTACCGA 117

GGGACC-GCGTGCCTTTGTTTTACTCCTAATGGTCTTAACCCGGATTCACCCCCC-AGAA 174 GGGACC-GCGTACCTTTGTTTTACTCCTAATGGTCTTAACCCGGATTCCTCCCCC-AGAA 176 AGGACC-GCGTGCCTTAGTTTTACTCCTAATGGTCTTAACCCGGATTCACCCCCC-AGAA 175 TGGATCAGCGCACCTTTGTTTTACTCCTAATGGTCTTAACCCGGCTTCACCCCCC-AGAA 177 GGAAT--GCGTACCTTTGTTCCACTCCTAATGGTCTTGACCCGGATTCATCCCCC-AGAA 178 CGGACC-GCGTGCCCTTGTTTTACTCCTAATGGTCTTAGCCCGGATTCGCCCCCCCAGAA 176 AGGACC-GCGTGCCTTAGTTTTACTCCTAATGGTCTTAACCCGGATTCACCCCCC-AGAA 175

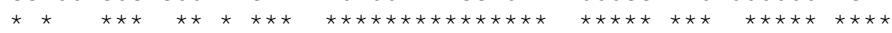

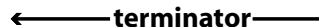

CCCGGGTTTTTTTTGCCT 192 CCCGGGTTTTTTTTGTGT 194 CCCGGGTTTTTTTTGCCC 193 TCCGGGTTTTTTTTGCCT 195 CCCGGGTTTTTTTTATCC 196 CCCGGGTTTTTTTTGCCT 194 CCCGGGTTTTTTTTGCCC 193 $\stackrel{* * * * * * * * * * * * *}{\longrightarrow}$

b

$1 \mathrm{~kb}$

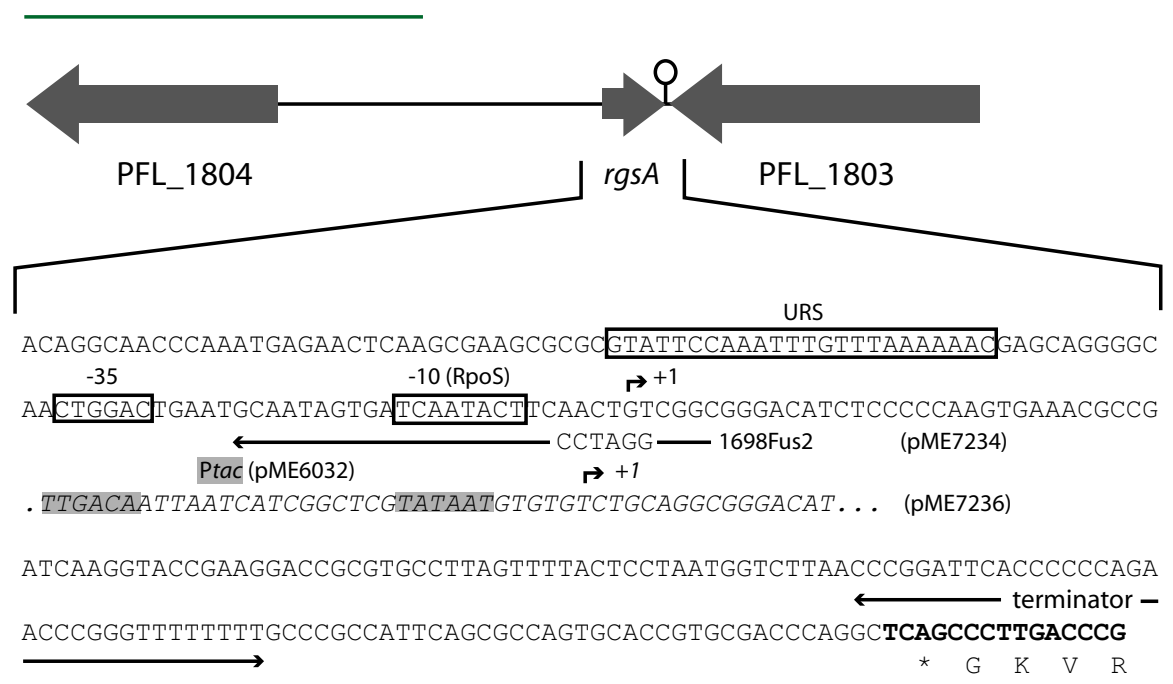

Figure 3

Conservation of IgR 1698 in pseudomonads. a. Alignment of the $P$. aeruginosa PAOI IgR 1698 with homologous sequences present in $P$. fluorescens PfO-I, $P$. putida KT2440, $P$. fluorescens Pf-5, P. syringae pv. tomato DC3000 and P. fluorescens SBW25. The IgR 1698 sequence of $P$. fluorescens CHA0, which was determined experimentally in this study, is

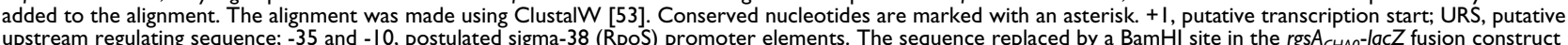
upstream regulating sequence; -35 and -10 , postulated sigma-38 (RpoS) promoter elements. The sequence replaced by a BamHI site in the rgs $A_{C H A} \sigma^{-l a c Z}$ fusion construct
pME7234 is underlined. b. Organization of the 2.4-kb rgsA gene region in strain $\mathrm{CHAO}$. The sequence of the downstream ORF PFL I803 is shown in boldface with its translated sequence below. The 1698 Fus2 primer employed to construct PME7234 is shown as an arrow, with the cloning BamHI site detailed. Part of the sequence of the rsgA $A_{C H A O}$ overexpressing construct PME7236 is shown in italics; the tac promoter (Ptac) is indicated by grey boxes and its transcription start by $+I$. 
a

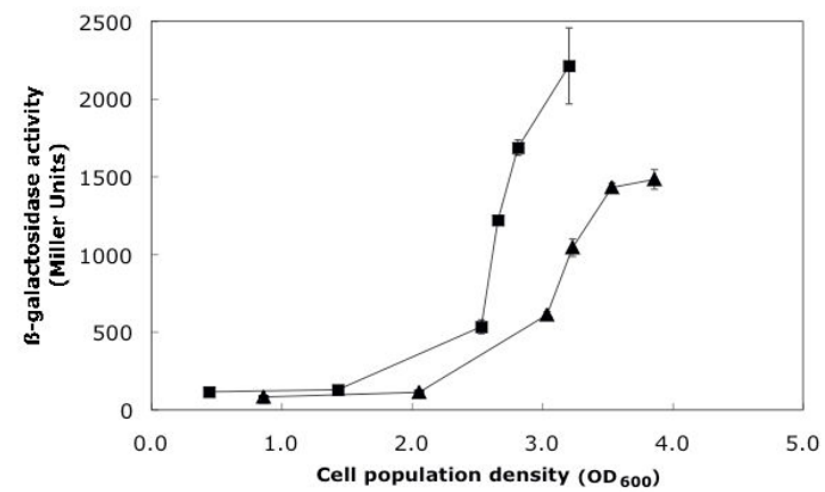

b

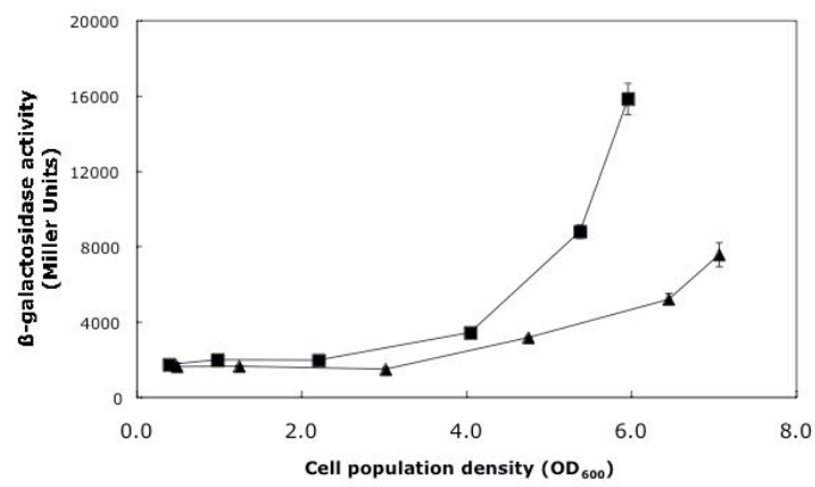

C

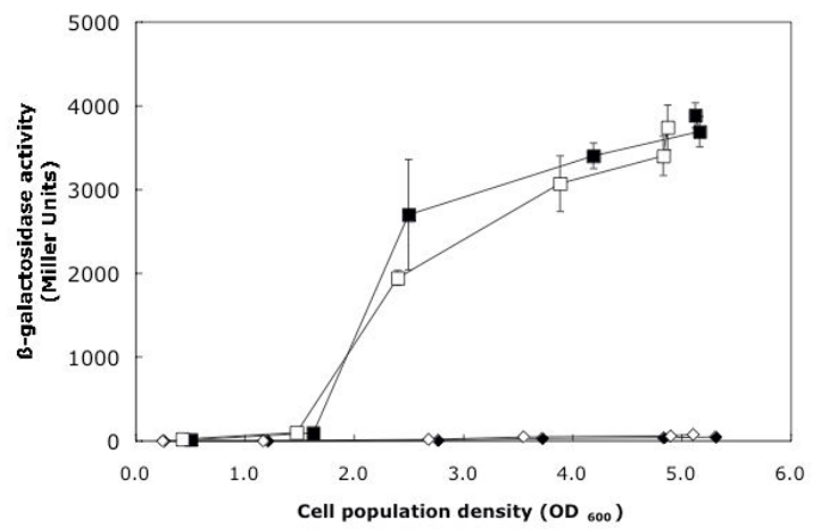

d

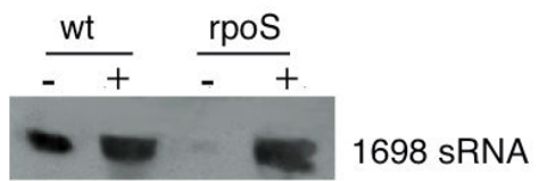

\section{Figure 4}

Expression of rgsA-lacZ and $h c n A$ '-'lacZ fusions. a. $\beta$-Galactosidase activities of an $r g S A_{P A O I}$-lacZ transcriptional fusion (pME7235) were determined in the $P$. aeruginosa wildtype PAOI (squares) and in the gacA mutant PAO628I (triangles). b. $\beta$-Galactosidase activities of an rgsA ${ }_{C H A O} 0^{-l a c Z}$ transcriptional fusion (pME7234) were determined in the P. fluorescens wild-type CHAO (squares) and in the gacA mutant CHA89 (triangles). $c$. $\beta$-Galactosidase activities of a chromosomal henA'-'lacZ translational fusion were determined in a $P$. fluorescens wild-type context (CHA207) carrying the empty PME6032 vector (filled squares) or the rgsA overexpressing plasmid pME7236 (open squares), and in the rsm XYZ triple mutant (CHAI I45) carrying PME6032 (filled diamonds) or PME7236 (open diamonds). I mM IPTG was added when the cultures were inoculated. Each value in a, b and c is the average from three different cultures \pm standard deviation. $\mathbf{d}$. Verification of the overexpression of RgsA sRNA by Northern blot. Total RNA was purified from cultures of P. fluorescens CHAO (wild type) and CHA815 (rpoS mutant) grown to stationary phase, carrying the empty PME6032 vector (-) or the rgsA overexpressing plasmid pME7236 $(+)$. 


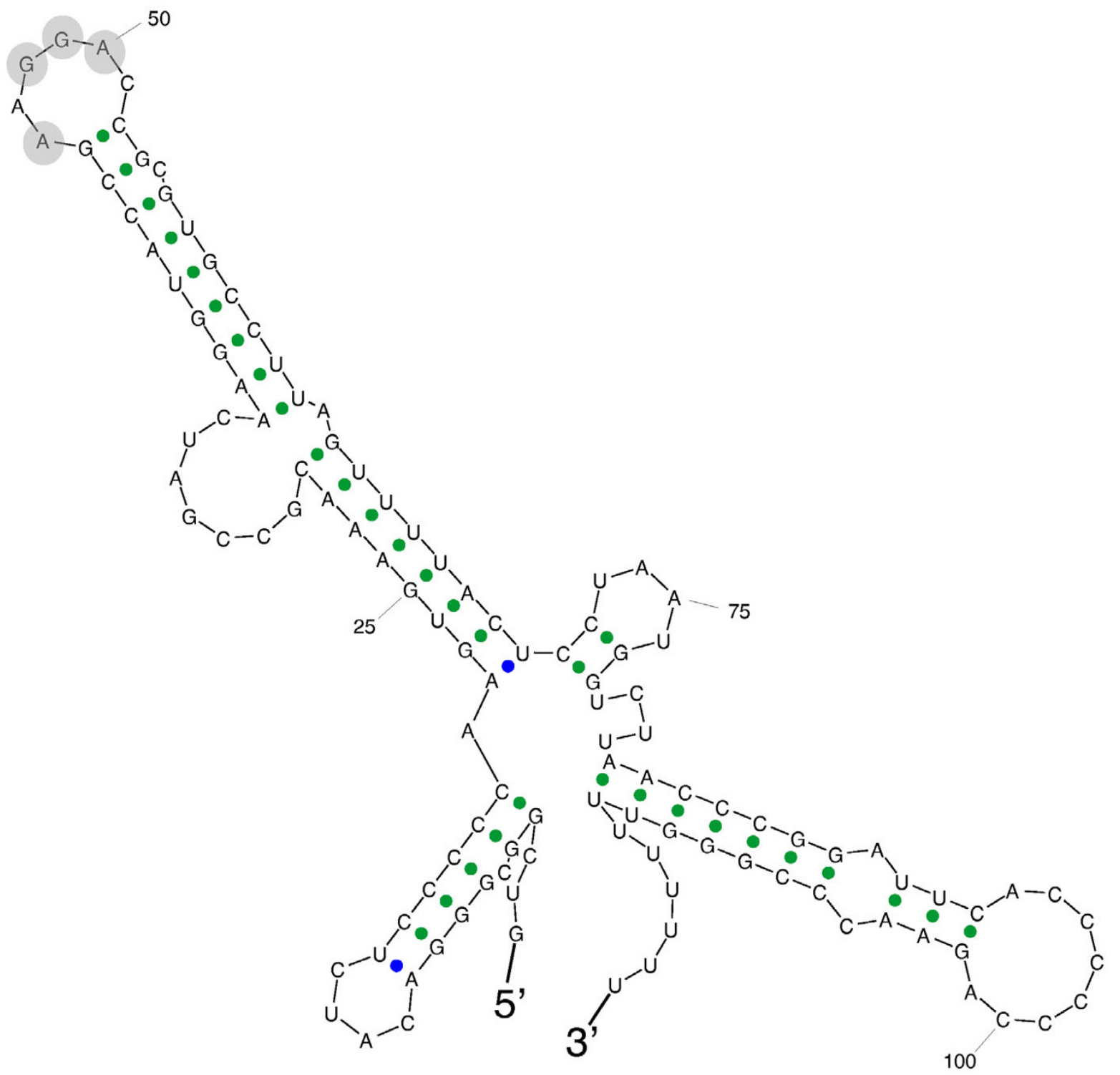

\section{Figure 5}

Secondary structure of RgsA sRNA from P. fluorescens CHAO. Secondary structure of RgsA as predicted by the SFold program [57]. A predicted RsmA-binding motif (ANGGA) at position 46-50 in an unpaired region is highlighted by grey circles.

'lacZ expression in the rsmXYZ triple mutant (CHA1145/ pME7236), which was indistinguishable from the strain carrying the vector alone (CHA1145/pME6032) (Figure 4c). In a control experiment, we verified $r g s A_{C H A O}$ overexpression by plasmid pME7236. Total RNA was extracted from strains carrying either pME7236 or the vector pME6032 and the amount of RgsA sRNA expressed in the cells was evaluated by Northern blotting. Overexpression of RgsA sRNA was detectable in the wild-type strain CHA0 and even more clearly in the rpoS mutant CHA815 (Figure 4d). In conclusion, the single RsmA-binding motif of RgsA was unable to derepress $h c n A$ expression in P. fluorescens, confirming earlier evidence that multiple GGA motifs are required in sRNAs for effective sequestration of RsmA-like proteins [33].

The Gac/Rsm cascade modulates the response of $P$. fluorescens to stress imposed by hydrogen peroxide [14]. We constructed an rgsA deletion mutant of strain CHAO and tested its survival after a 30-min exposure to $40 \mathrm{mM} \mathrm{H}_{2} \mathrm{O}_{2}$ 
in NYB with shaking. This experiment was carried out three times with triplicate cultures. Only $69 \pm 16 \%$ of the mutant cells survived, compared with $94 \pm 12 \%$ surviving wild type cells. (The initial viable count was set at $100 \%$.) Thus, survival was significantly $(P<0.05)$ higher in the wild type than in the mutant. Overexpression of $r g s A$ afforded no significant effect. These results suggest that RgsA may contribute to oxidative stress response.

\section{Discussion}

The screening procedure adopted in our study enabled us to find evidence for 15 sRNAs in P. aeruginosa and other Pseudomonas spp. The identification of four of these sRNAs can be considered as a validation of the method, as they are either widespread in bacteria (4.5S RNA, RNase P RNA) or have been previously described in $P$. aeruginosa (PrrF1, PrrF2) [19]. Three additional sRNAs (491, 1698, 1887) confirm the existence of molecules that were previously identified by Livny et al. [20], and the observed lengths of these sRNAs are similar in both studies. Although our computational approaches are similar to those used by Livny et al. [20], we obtained a different output. On the one hand, we found evidence for eight new sRNAs. It is likely that by applying a 93\% confidence threshold in the prediction of rho-independent terminators with TransTerm, we expanded the spectrum of intergenic regions considered to carry sRNA genes, whereas Livny et al. [20] had used a 96\% threshold. On the other hand, 14 sRNAs detected by Livny et al. [20] were not identified in this study, either because the IgRs that produce them were discarded by our configuration of the QRNA program (this concerns sRNAs P1, P8, P9, P15, P18, P32, P34 and P35) or because we did not subject all 130 candidate IgRs to Northern blot analysis (this concerns our IgRs 967, 1023, 1554, 1633, 2429 and 2680, which correspond to P10, P11, P13, P14, P27 and P36, respectively). By introducing two additional genomes into the analysis, i.e., those of $P$. fluorescens PfO- 1 and $P$. fluorescens Pf-5, and by considering only the most widely conserved candidates we also demanded a higher level of conservation than did Livny et al. [20].

RsmY and RsmZ, the RsmA-binding sRNAs previously described in $P$. aeruginosa $[16,34]$, were not revealed in our present study. The reasons for this may be that the RsmZ sRNAs of strains PAO1 and CHA0 have only 63\% sequence identity (according to a needle global alignment; [35]), just below the 65\% cut-off used. Although the RsmY sRNAs of strains PAO1 and CHA0 share $73 \%$ overall sequence identity in a needle alignment, the conserved segments of the RsmY sRNAs obtained with the BLASTn searches were short and shared an elevated sequence identity. In such cases the QRNA program, which needs sufficient substitutions that preserve secondary structures or codon bias, fails to identify and catego- rize the RNAs, explaining the absence of RsmY from our study.

In both $P$. aeruginosa PAO1 and $P$. fluorescens CHAO the $\mathrm{Gac} / \mathrm{Rsm}$ cascade regulates the expression of exoproducts such as HCN. In these organisms, a double rsmY rsmZ and triple rsmX rsmY rsmZ mutant, respectively, have the same exoproduct phenotype as gacA mutants $[10,16]$. However, in strain CHA0, GacA has an additional function as a regulator of rpos expression and, consequently, of the response to oxidative stress [14]. This raised the question of whether there might be further GacA-controlled sRNAs, which might be involved in stress response. This idea motivated us to test the sRNAs listed in Table 1 for regulation by GacA. In both strains PAO1 and CHA0, the RgsA (1698) sRNA was found to have reduced expression in gacA mutants, by comparison with the wild-type strains (Figure 2). Moreover, RpoS was needed for $r g s A$ induction in both strains during stationary phase (Figure 2). We confirmed this regulation in both $P$. aeruginosa and $P$. fluorescens by measuring the expression of rgsA-lacZ fusion constructs (Figures $4 \mathrm{a}$ and $4 \mathrm{~b}$ ). We also found that the overexpressed RgsA sRNA was unable to relieve translational repression of the hcnA gene in P. fluorescens (Figure $4 \mathrm{c}$ ), which is consistent with the fact that this sRNA has only a single GGA motif. Previously, it was shown that an RsmY mutant having a single GGA motif has lost the ability to bind the RsmA and RsmE proteins [33].

In response to $\mathrm{H}_{2} \mathrm{O}_{2}$ stress, a $P$. fluorescens mutant deleted for the rgsA gene showed a reduced ability to survive, compared with the wild type. The mechanism by which this protective effect of RgsA occurs remains to be discovered.

\section{Conclusion}

In this study we have found evidence for eight new sRNAs in $P$. aeruginosa. This brings the total of detected sRNAs to almost 30 in this organism. For the vast majority of them, the physiological roles are unknown. We discovered that the RgsA sRNA, which was termed P16 by Livny et al. [20], is transcribed from an RpoS-dependent promoter under positive, probably indirect control of GacA in P. aeruginosa PAO1 as well as in P. fluorescens CHA0. In the latter organism, the RgsA sRNA appears to be unable to sequester the RsmA and RsmE proteins and is unlikely to have a role in the regulation of exoproduct formation, but helps protect the bacterium from $\mathrm{H}_{2} \mathrm{O}_{2}$.

\section{Methods}

\section{Bacterial strains and growth conditions}

We used $P$. aeruginosa PAO1 (ATCC 15692) and its derivatives PAO1-rpoS [30] and PAO6281 (gacA:: $\Omega-S m / S p)$ [13], P. fluorescens CHAO [36], CHA89 (gacA::Km ${ }^{\mathrm{r}}$ [37],

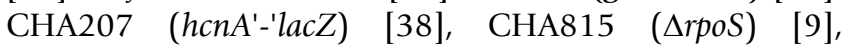
CHA1145 (rsmXYZ, honA'-'lacZ) [10] and CHA1181 
( $\Delta r g s A$, this study). E. coli DH5 $\alpha$ [39] served for gene cloning. Strains were routinely grown in nutrient yeast broth (NYB; 2.5\% [wt/vol] nutrient broth, 0.5\% [wt/vol] yeast extract) with shaking, or on nutrient agar (4\% [wt/vol] blood agar base, $0.5 \%$ [wt/vol] yeast extract). When required, ampicillin at $100 \mu \mathrm{g} \mathrm{ml}^{-1}$ or tetracycline at $25 \mu \mathrm{g}$ $\mathrm{ml}^{-1}$ (100 $\mu \mathrm{g} \mathrm{ml}^{-1}$ for pseudomonads) were added. For some RNA extractions, strains were also grown in GGP medium [40] or in MME minimal medium [41]. To monitor $\beta$-galactosidase expression qualitatively, 5-bromo-4chloro-3-indolyl- $\beta$-D-galactoside (Xgal) was incorporated into solid media at a final concentration of $0.02 \%$. Routine incubation temperatures were $37^{\circ} \mathrm{C}$ for $E$. coli and $P$. aeruginos $a$ and $30^{\circ} \mathrm{C}$ for $P$. fluorescens. Survival of stationary phase $P$. fluorescens was assayed in NYB following $\mathrm{H}_{2} \mathrm{O}_{2}$ stress as described previously [14]. Statistical significance was assessed by Student's t-test.

\section{DNA manipulations and cloning procedures}

DNA manipulations were carried out according to standard procedures [39]. Plasmid isolation was performed using the cetyl-trimethyl-ammonium bromide method (CTAB) [42] for small preparations, and the JetStar kit (Genomed $\mathrm{GmbH}$ ) for large preparations. DNA fragments were purified from agarose gels with the MinElute Gel Extraction Kit or the Qiaquick Gel Extraction Kit (Qiagen Inc.). Transformation of the strains was done by electroporation [43]. DNA sequencing was carried out by Microsynth (Microsynth AG). Polymerase chain reaction was carried out as previously described [11].

\section{Plasmid constructions}

To generate pME7234 carrying a transcriptional lacZ fusion to the rgsA gene from $P$. fluorescens CHA0, a 510-bp fragment containing the rgs $A$ sRNA promoter was amplified from chromosomal DNA by PCR using primers 1698Fus1 (EcoRI) and 1698Fus2 (BamHI) listed in Additional file 3, digested by EcoRI and BamHI, and inserted into EcoRI/BamHI-cut pBLS (pBluescript II KS+ cloning vector, ColE1 replicon, Ap ${ }^{\mathrm{R}}$, Stratagene). After sequencing, the fragment was cloned into the shuttle vector pME6016 [44]. The resulting plasmid pME7234 carries the $\operatorname{rgs} A_{C H A O}$ promoter controlling the expression of the lacZ gene. Similarly, we constructed pME7235 carrying a transcriptional lacZ fusion to the rgs A gene from $P$. aeruginosa PAO1 using primers 1698Fus3 (EcoRI) and 1698Fus4 (BamHI) (Additional file 3 ) and analogous cloning steps.

To overexpress rgsA from $P$. fluorescens CHA0, plasmid pME7236 was constructed in several steps. First, a 180-bp fragment containing the rgsA gene was amplified from chromosomal DNA using the primers 1698Sur4 (EcoRI, PstI) and 1698Sur2 (HindIII) (Additional file 3), digested with EcoRI and HindIII, and inserted into EcoRI/HindIIIcut pBLS. A 200-bp fragment was then excised from pBLS with EcoRI and KpnI and cloned into pME6032 [9]. The Shine-Dalgarno sequence carried by pME6032 was removed, as it is unsuitable for the expression of a noncoding sRNA gene, by a second round of PCR using the primers 6032K (HpaI) and 1698Sur6 (PstI) (Additional file 3), digestion by HpaI and PstI, and cloning. The resulting construct pME7236 carries the pME6032 tac promoter $13 \mathrm{nt}$ upstream of the $\operatorname{rgs} A+1$ site. The introduction of the PstI restriction site downstream the tac promoter added 3 nt and modified 2 nt of the RgsA sRNA at the 5' end (5'TCTGCAGGCGGG... instead of 5'-GTCGGCGGG...).

\section{Construction of an rgsA mutant of $P$. fluorescens}

A deletion of the rgs A gene in the $P$. fluorescens CHA0 chromosome was made as follows. A 860-bp fragment containing the upstream region and the rgsA promoter was amplified by PCR with primers 1698DelE (EcoRI) and 1698Del3 (NcoI) (Additional file 3). A 750-bp fragment containing the rgs A terminator and most of the downstream PFL_1803 gene was amplified by PCR with primers 1698Del4 (NcoI) and 1698DelX (XbaI) (Additional file 3 ). Both fragments were digested with NcoI and ligated together; in the resulting $\sim 1.6-\mathrm{kb}$ fragment there remained $11 \mathrm{bp}$ between the transcription start site and the terminator of the rgsA gene. The fragment was digested with EcoRI and $\mathrm{XbaI}$ and cloned into pME3087 (suicide vector; ColE1 replicon; Tcr; [36]). E. coli DH5 $\alpha$ was transformed with the resulting pME3087 derivative and used in a triparental mating with the helper HB101/pME497 [45]. In this way the deleted $r g s A$ gene $(\Delta r g s A)$ was introduced into CHA0, giving CHA1181.

\section{Computational search parameters in the screening for sRNAs}

Our screening was limited to the IgRs of the P. aeruginosa PAO1 genome having a length exceeding $50 \mathrm{bp}$. The corresponding 3168 sequences were listed in FASTA format and compared by BLASTn to the genome sequences of $P$. putida KT2440 [46], P. syringae pv. tomato DC3000 [47], P. fluorescens SBW25 [48], P. fluorescens Pf0-1) [49], and P. fluorescens Pf-5 [50]. We fixed a cut-off at 65\% sequence identity. The PAO1 sequences fulfilling this criterion, together with the homologous sequences of at least another Pseudomonas strain, were given as input data into the program QRNA [5]. Briefly, this program is able to compare each of the PAO1 sequences with a paired sequence, and tests the pattern of substitutions observed in the pairwise alignment of two homologous sequences. Three models of substitution are analyzed. Model (i) assumes that mutations occur in a position-independent manner (called OTH); model (ii) assumes that in homologous coding regions mutations often result in conservative amino acid substitutions (called COD); model (iii) assumes that the pattern of mutations significantly conserves the secondary structure in a homologous RNA 
(called RNA). For each alignment QRNA establishes scores according to each model and calculates to which category the aligned sequences most probably belong. For IgRs, sequences can be described as COD if after the alignment with their homologous sequences they do not have enough substitutions reflecting secondary structure conservation and present a (probably fortuitous) codon usage bias. Using QRNA we obtained a list of 162 intergenic regions that share coding (COD) or structural homology (RNA) with at least one related genome sequence (see Additional file 1).

\section{Sequence analysis tools}

FUZZNUC, a free access nucleic acid pattern search program [35], was used to search for conserved motifs in IgRs, e.g. for RpoD $\left(\sigma^{70}\right)$ binding sites (TTGACAN $_{(17)}$ TATAAT), RpoN $\left(\sigma^{54}\right)$ binding sites TGGCACN $_{(5)}$ TTGCW, where $\mathrm{W}$ is A or T, based on Barrios et al. [51]) or for the -10 element of Rpos $\left(\sigma^{38}\right)$-binding sites $\left(\mathrm{TGN}_{(0-2)} \mathrm{CCATACT}\right.$, according to Lacour et al. [52]). We used CLUSTALW [53] for multiple sequence alignments and TransTerm [24] to identify rho-independent terminators in IgRs. The analysis was done using the entire PAO1 chromosomal sequence as the template and the list of PAO1 ORFs (such that the program can distinguish the intragenic from the intergenic parts of the chromosomal sequence); both were obtained from the $P$. aeruginosa PAO1 sequencing project site [54]. The confidence threshold was set to $93 \%$.

\section{RNA extraction and Northern blots}

RNAs used for Northern blot analysis were isolated using a hot acid phenol extraction protocol, based on the technique described by Massé et al. [55]. The original protocol was modified as follows: $5 \mathrm{ml}$ of cell culture was centrifuged and resuspended in $5 \mathrm{ml}$ of TKM buffer $(10 \mathrm{mM}$ Tris-HCl, $10 \mathrm{mM} \mathrm{KCl}, 5 \mathrm{mM} \mathrm{MgCl}_{2}$, $\mathrm{pH}$ 7.5), before mixing with lysis buffer $(320 \mathrm{mM}$ Na acetate, $8 \%$ [wt/vol] $\mathrm{Na}$ dodecylsulfate, $16 \mathrm{mM}$ EDTA, pH 4.6, treated with diethyl-pyrocarbonate [DEPC] and autoclaved). DIGlabelled probes were obtained as follows: PCR fragments were synthesized with $P$. aeruginosa or $P$. fluorescens genomic DNA as the template and pairs of primers listed in the Additional file 3. For each probe, the first primer was designed to hybridize to the proximal part of the upstream ORF (forward primer, indicated by F) and the second to hybridize to the proximal part of the downstream ORF (reverse primer, indicated by $\mathrm{R}$ ). The fragments obtained corresponded to the IgRs to be analyzed and were then used as templates for a second PCR, which was carried out with the same pairs of primers as before, but in the presence of DIG DNA labeling mix (DNA labeling Mix, $10 \times$ conc., Roche). RNAs ( $5 \mu$ g per lane) were separated on a denaturing urea-polyacrylamide gel and analyzed by Northern blotting as previously described [11], with minor modifications: RNAs were transferred by electroblotting ( $20 \mathrm{~min}$ at $150 \mathrm{~mA}$ ) onto a charged Nylon membrane (Hybond-N+ ${ }^{+}$, GE-Amersham) and revealed by hybridization with the DIG-labeled probes described above and exposure to a light-sensitive film (Super RX, Fujifilm). 5S rRNA served as loading control. For this purpose, a 5S-rDNA probe was synthesized with primers 5SrRNA-1 and 5S-rRNA-2 (Additional file 3) and DIGlabeled. The membranes could be used a second time for Northern blot detection of $5 S$ rRNA. To completely detach the probe previously hybridized, membranes were rinsed with DEPC-treated $\mathrm{H}_{2} \mathrm{O}$ and immersed twice in $0.2 \mathrm{M}$ $\mathrm{NaOH}$ containing $0.1 \% \mathrm{Na}$ dodecylsulfate for $15 \mathrm{~min}$. The membranes were then rinsed with $2 \times$ SSC solution [39] and used in further Northern blots.

\section{$\beta$-Galactosidase assays}

$P$. fluorescens cells were grown in $20 \mathrm{ml}$ of NYB, in $100 \mathrm{ml}$ Erlenmeyer flasks. Triton X-100 (0.1\% wt/vol) was added to the cultures to avoid cell aggregation. Samples were taken during various growth phases and permeabilized with $5 \%$ toluene. $\beta$-Galactosidase activities were then measured according to the Miller method [56].

\section{Abbreviations}

BLAST, Basic Local Alignment Search Tool; CTAB, cetyltrimethyl-ammonium bromide; DEPC, di-ethyl-pyrocarbonate; DIG, digoxigenin; EDTA, ethylene-di-aminetetraacetic acid; GGP, iron-limited medium; HCN, hydrogen cyanide; IgR, intergenic region; $M M E$, minimal medium E; NYB, nutrient yeast broth; SRNA, small RNA; URS, upstream regulating sequence; Xgal, 5-bromo-4chloro-3-indolyl- $\beta$-D-galactoside;

\section{Authors' contributions}

NG designed and carried out experiments, and drafted manuscript; $\mathrm{SH}$ and TJ executed the bioinformatics search; CV, EK and CR performed Northern blots; DH directed research and wrote the manuscript.

\section{Additional material}

\section{Additional file 1}

Intergenic regions. List of IgRs of Pseudomonas aeruginosa PAO1 giving a positive result in QRNA analysis.

Click here for file

[http://www.biomedcentral.com/content/supplementary/1471-

2164-9-167-S1.xls]

\section{Additional file 2}

Predicted coordinates of three sRNA genes. Figure showing the predicted coordinates of sRNA genes in IgRs 645, 1887 and 2315. Click here for file

[http://www.biomedcentral.com/content/supplementary/14712164-9-167-S2.pdf] 


\section{Additional file 3}

Primers. Primers used in this study for Northern blots and recombinant DNA work.

Click here for file

[http://www.biomedcentral.com/content/supplementary/14712164-9-167-S3.xls]

\section{Acknowledgements}

This work was supported by a Genomics Project of the University of Lausanne and the Swiss National Foundation.

\section{References}

I. Livny , Waldor MK: Identification of small RNAs in diverse bacterial species. Curr Opin Microbiol 2007, 10:96-101.

2. Wassarman KM, Zhang A, Storz G: Small RNAs in Escherichia coli. Trends Microbiol 1999, 7:37-45.

3. Argaman L, Hershberg R, Vogel J, Bejerano G, Wagner EG, Margalit $H$, Altuvia S: Novel small RNA-encoding genes in the intergenic regions of Escherichia coli. Curr Biol 200 I, II:94 I-950.

4. Lenz DH, Miller MB, Zhu J, Kulkarni RV, Bassler BL: CsrA and three redundant small RNAs regulate quorum sensing in Vibrio cholerae. Mol Microbiol 2005, 58: I I86-1202

5. Rivas E, Eddy SR: Noncoding RNA gene detection using comparative sequence analysis. BMC Bioinformatics $200 \mathrm{I}, \mathbf{2 : 8}$

6. Silvaggi JM, Perkins JB, Losick R: Genes for small, noncoding RNAs under sporulation control in Bacillus subtilis. J Bacteriol 2006, I 88:532-54I.

7. Afonyushkin T, Vecerek B, Moll I, Bläsi U, Kaberdin VR: Both RNase $E$ and RNase III control the stability of sodB mRNA upon translational inhibition by the small regulatory RNA RyhB. Nucleic Acids Res 2005, 33:1678-1689.

8. Babitzke P, Romeo T: CsrB sRNA family: sequestration of RNA-binding regulatory proteins. Curr Opin Microbiol 2007, 10:156-163.

9. Heeb S, Blumer C, Haas D: Regulatory RNA as mediator in GacA/RsmA-dependent global control of exoproduct formation in Pseudomonas fluorescens CHA0. J Bacteriol 2002, 184: 1046-1056.

10. Kay E, Dubuis C, Haas D: Three small RNAs jointly ensure secondary metabolism and biocontrol in Pseudomonas fluorescens CHAO. Proc Natl Acad Sci USA 2005, 102:17136-17141.

II. Valverde C, Heeb S, Keel C, Haas D: RsmY, a small regulatory RNA, is required in concert with RsmZ for GacA-dependent expression of biocontrol traits in Pseudomonas fluorescens CHA0. Mol Microbiol 2003, 50:1361-1379.

12. Aarons $S$, Abbas $A$, Adams $C$, Fenton $A, O$ 'Gara F: A regulatory RNA (PrrB RNA) modulates expression of secondary metabolite genes in Pseudomonas fluorescens FII3. J Bacteriol 2000, 182:3913-3919.

13. Reimmann C, Valverde C, Kay E, Haas D: Posttranscriptional repression of GacS/GacA-controlled genes by the RNA-binding protein RsmE acting together with RsmA in the biocontrol strain Pseudomonas fluorescens CHA0. J Bacteriol 2005, 187:276-285.

14. Heeb S, Valverde C, Gigot-Bonnefoy C, Haas D: Role of the stress sigma factor RpoS in GacA/RsmA-controlled secondary metabolism and resistance to oxidative stress in Pseudomonas fluorescens CHAO. FEMS Microbiol Lett 2005, 243:25I-258.

15. Haas D, Défago G: Biological control of soil-borne pathogens by fluorescent pseudomonads. Nat Rev Microbiol 2005, 3:307-319.

16. Kay E, Humair B, Dénervaud V, Riedel K, Spahr S, Eberl L, Valverde $C$, Haas D: Two GacA-dependent small RNAs modulate the quorum-sensing response in Pseudomonas aeruginosa. J Bacteriol 2006, 188:6026-6033.

17. Reimmann C, Beyeler M, Latifi A, Winteler H, Foglino M, Lazdunski A, Haas D: The global activator GacA of Pseudomonas aeruginosa PAO positively controls the production of the autoin- ducer $\mathbf{N}$-butyryl-homoserine lactone and the formation of the virulence factors pyocyanin, cyanide, and lipase. Mol Microbiol 1997, 24:309-319.

18. Pessi G, Williams F, Hindle Z Heurlier K, Holden MT, Cámara M, Haas D, Williams $P$ : The global posttranscriptional regulator RsmA modulates production of virulence determinants and $\mathbf{N}$-acylhomoserine lactones in Pseudomonas aeruginosa. J Bacteriol 200I, 183:6676-6683.

19. Wilderman PJ, Sowa NA, FitzGerald DJ, FitzGerald PC, Gottesman S, Ochsner UA, Vasil ML: Identification of tandem duplicate regulatory small RNAs in Pseudomonas aeruginosa involved in iron homeostasis. Proc Natl Acad Sci USA 2004, I0 I:9792-9797.

20. Livny J, Brencic A, Lory S, Waldor MK: Identification of 17 Pseudomonas aeruginosa sRNAs and prediction of sRNA-encoding genes in 10 diverse pathogens using the bioinformatic tool sRNAPredict2. Nucleic Acids Res 2006, 34:3484-3493.

21. Wassarman KM, Repoila F, Rosenow C, Storz G, Gottesman S: Identification of novel small RNAs using comparative genomics and microarrays. Genes Dev 2001, 15:1637-165I.

22. Gottesman S: The small RNA regulators of Escherichia coli : roles and mechanisms. Annu Rev Microbiol 2004, 58:303-328.

23. Hershberg R, Altuvia $S$, Margalit $H$ : A survey of small RNA-encoding genes in Escherichia coli. Nucleic Acids Res 2003, 31: I8I3-1820.

24. Ermolaeva MD, Khalak HG, White O, Smith HO, Salzberg SL: Prediction of transcription terminators in bacterial genomes. Mol Biol 2000, 30 I:27-33.

25. Toschka HY, Struck JC, Erdmann VA: The 4.5S RNA gene from Pseudomonas aeruginosa. Nucleic Acids Res 1989, 17:31-36.

26. Li Z, Pandit S, Deutscher MP: 3' exoribonucleolytic trimming is a common feature of the maturation of small, stable RNAs in Escherichia coli. Proc Natl Acad Sci USA 1998, 95:2856-286I.

27. Vogel J, Bartels V, Tang TH, Churakov G, Slagter-jäger JG, Hüttenhofer A, Wagner EG: RNomics in Escherichia coli detects new sRNA species and indicates parallel transcriptional output in bacteria. Nucleic Acids Res 2003, 3 I:6435-6443.

28. Vitreschak AG, Rodionov DA, Mironov AA, Gelfand MS: Regulation of riboflavin biosynthesis and transport genes in bacteria by transcriptional and translational attenuation. Nucleic Acids Res 2002, 30:3|4|-3|5|.

29. Winkler WC, Cohen-Chalamish S, Breaker RR: An mRNA structure that controls gene expression by binding FMN. Proc Natl Acad Sci USA 2002, 99:15908-15913.

30. Jørgensen F, Bally M, Chapon-Hervé V, Michel G, Lazdunski A, Williams P, Stewart GS: RpoS-dependent stress tolerance in Pseudomonas aeruginosa. Microbiology 1999, 145:835-844.

31. Typas A, Becker G, Hengge R: The molecular basis of selective promoter activation by the sigmaS subunit of RNA polymerase. Mol Microbiol 2007, 63:1296-1306.

32. Wexler M, Sargent F, Jack RL, Stanley NR, Bogsch EG, Robinson C, Berks BC, Palmer T: TatD is a cytoplasmic protein with DNase activity. No requirement for TatD family proteins in Secindependent protein export. J Biol Chem 2000, 275: I 6717-16722.

33. Valverde $C$, Lindell M, Wagner EG, Haas D: A repeated GGA motif is critical for the activity and stability of the riboregulator RsmY of Pseudomonas fluorescens. J Biol Chem 2004, 279:25066-25074.

34. Heurlier K, Williams F, Heeb S, Dormond C, Pessi G, Singer D, Cámara $M$, Williams $P$, Haas $D$ : Positive control of swarming, rhamnolipid synthesis, and lipase production by the posttranscriptional RsmA/RsmZ system in Pseudomonas aeruginosa PAOI. J Bacteriol 2004, I 86:2936-2945.

35. Rice P, Longden I, Bleasby A: EMBOSS: the European Molecular Biology Open Software Suite. Trends Genet 2000, 16:276-277.

36. Voisard C, Bull CT, Keel C, Laville J, Maurhofer M, Schnider M, Défago G, Haas D: Biocontrol of root diseases by Pseudomonas fluorescens CHAO: current concepts and experimental approaches. In Molecular ecology of rhizosphere microorganisms Edited by: O'Gara F, Dowling DN, Boesten B. Weinheim, Germany: VCH Publisher; 1994:67-89.

37. Laville J, Voisard C, Keel C, Maurhofer M, Défago G, Haas D: Global control in Pseudomonas fluorescens mediating antibiotic synthesis and suppression of black root rot of tobacco. Proc Natl Acad Sci USA 1992, 89:1562-1566.

38. Blumer C, Heeb S, Pessi G, Haas D: Global GacA-steered control of cyanide and exoprotease production in Pseudomonas fluo- 
rescens involves specific ribosome binding sites. Proc Natl Acad Sci USA 1999, 96: I4073-I 4078.

39. Sambrook J, Russell DW: Molecular cloning: A Laboratory Manual. 3rd edition. Cold Spring Harbor, NY: Cold Spring Harbor Laboratory Press; 2001.

40. Carmi R, Carmeli S, Levy E, Gough FJ: (+)-(S)-dihydroaeruginoic acid, an inhibitor of Septoria tritici and other phytopathogenic fungi and bacteria, produced by Pseudomonas fluorescens. J Nat Prod 1994, 57:1200-1205.

4I. Vogel HJ, Bonner DM: Acetylornithinase of Escherichia coli : partial purification and some properties. I Biol Chem 1956, 218:97-106.

42. Del Sal G, Manfioletti G, Schneider C: A one-tube plasmid DNA mini-preparation suitable for sequencing. Nucleic Acids Res 1988, 16:9878.

43. Farinha MA, Kropinski AM: High efficiency electroporation of Pseudomonas aeruginosa using frozen cell suspensions. FEMS Microbiol Lett 1990, 58:221-225.

44. Schnider-Keel U, Seematter A, Maurhofer M, Blumer C, Duffy B, Gigot-Bonnefoy C, Reimmann C, Notz R, Défago G, Haas D, et al:: Autoinduction of 2,4-diacetylphloroglucinol biosynthesis in the biocontrol agent Pseudomonas fluorescens CHAO and repression by the bacterial metabolites salicylate and pyoluteorin. J Bacteriol 2000, 182: 12 15-1225.

45. Voisard C, Rella M, Haas D: Conjugative transfer of plasmid RPI to soil isolates of Pseudomonas fluorescens is facilitated by certain large RPI deletions. FEMS Microbiol Lett I988, 55:9-14.

46. Nelson KE, Weinel C, Paulsen IT, Dodson RJ, Hilbert H, Martins dos Santos VA, Fouts DE, Gill SR, Pop M, Holmes M, et al.: Complete genome sequence and comparative analysis of the metabolically versatile Pseudomonas putida KT2440. Environ Microbiol 2002, 4:799-808.

47. Buell CR, Joardar V, Lindeberg M, Selengut J, Paulsen IT, Gwinn ML, Dodson RJ, Deboy RT, Durkin AS, Kolonay JF, et al.: The complete genome sequence of the Arabidopsis and tomato pathogen Pseudomonas syringae pv. tomato DC3000. Proc Natl Acad Sci USA 2003, 100:10181-10186.

48. Pseudomonas fluorescens SBW25 [http://www.sanger.ac.uk/ Projects/P fluorescens]

49. Pseudomonas fluorescens Pf0-I [http://genome.jgi-psf.org/ finished microbes/psefl/psefl.home.html]

50. Pseudomonas fluorescens Pf-5 [http://cmr.tigr.org/tigr-scripts/ $\mathrm{CMR} /$ GenomePage.cgi?org=gpf]

51. Barrios H, Valderrama B, Morett E: Compilation and analysis of sigma(54)-dependent promoter sequences. Nucleic Acids Res 1999, 27:4305-4313.

52. Lacour S, Kolb A, Landini P: Nucleotides from -16 to -12 determine specific promoter recognition by bacterial sigmaSRNA polymerase. J Biol Chem 2003, 278:37160-37I68.

53. Thompson JD, Higgins DG, Gibson TJ: CLUSTAL W: improving the sensitivity of progressive multiple sequence alignment through sequence weighting, position-specific gap penalties and weight matrix choice. Nucleic Acids Res 1994, 22:4673-4680.

54. Pseudomonas aeruginosa PAOI [http://v2.pseudomonas.com/]

55. Massé E, Escorcia FE, Gottesman S: Coupled degradation of a small regulatory RNA and its mRNA targets in Escherichia coli. Genes Dev 2003, 17:2374-2383.

56. Miller JH: Assay of $\beta$-galactosidase. In Experiments in Molecular Genetics New York: Cold Spring Harbor Laboratory Press; 1972:352-355.

57. Ding Y, Chan CY, Lawrence CE: Sfold web server for statistical folding and rational design of nucleic acids. Nucleic Acids Res 2004, 32:W|35-I4I.
Publish with Biomed Central and every scientist can read your work free of charge

"BioMed Central will be the most significant development for disseminating the results of biomedical research in our lifetime. "

Sir Paul Nurse, Cancer Research UK

Your research papers will be:

- available free of charge to the entire biomedical community

- peer reviewed and published immediately upon acceptance

- cited in PubMed and archived on PubMed Central

- yours - you keep the copyright

Submit your manuscript here:

http://www.biomedcentral.com/info/publishing_adv.asp
BiolMedcentral 